\title{
Early detection of pulmonary dysfunction in the horse - an introduction
}

\author{
Conny Herholz', Reto Straub ${ }^{7}$, Andrea Imhof' und André Busato² \\ Departement für klinische Veterinärmedizin, Universität Bern ${ }^{1}$ und Maurice Müller Center Bern²
}

\begin{abstract}
Summary
Equine pulmonary function testing has long focused on horses with clinical signs of recurrent airway obstruction (RAO). The most widely used method is based on esophageal balloon pressure and pneumotachograph measurements. The disadvantages of this traditional pulmonary function test are its invasiveness, considerable cost and lack of sensitivity: airway obstruction can only be detected and measured, once it has become relatively severe and is clinically apparent. Volumetric capnography, on the other hand, is an effort-independent method of pulmonary function testing, which promises superior characteristics and performance. The goal of the work was to validate this method by the use of ultrasonic spirometry and capnography in the awake, spontaneous breathing horse.
\end{abstract}

Keywords: pulmonary function, volumetric capnopgraphy, pulmonary function test, Pulmology

\section{Zur Früherkennung von Lungenfunktionsstörungen beim Pferd - eine Einführung}

Seit langem wurden Lungenfunktionsprüfungen bei Pferden mit der klinischen Symptomatik einer rezidivierenden Atemwegsobstruktion (RAO) in die Untersuchung mit einbezogen. Die am häufigsten angewandte Methode zur Lungenfunktionsprüfung beim Pferd basiert auf Interpleuraldruckmessungen mit der Ösopagusballonsonde und Flow-Nolumenmessungen mit dem integrierten Pneumotachographen. Der Nachteil dieser herkömmlichen Methode zur Lungenfunktionsprüfung beim Pferd liegt in seiner Invasivität, Aufwendigkeit und Mangel an Sensitivität. Diese Methode erfasst Lungenfunktionseinbußen nur, wenn sie sich im fortgeschrittenen Stadium befinden und sich durch klinische Symptomatik bemerkbar machen. Die volumetrische Kapnographie ist eine ohne die Co-Operation des Probanden auskommende, nicht invasive Methode der Lungenfunktionsprüfung beim Pferd. Das Ziel der Arbeit war, diese Methode mit Hilfe der klinisch einfach zu applizierenden Ultraschall-Spirometrie und Kapnographie zu validieren. Der Artikel gibt eine Übersicht über die verschiedenen Stufen in der Validierung der volumetrischen Kapnographie beim Pferd und verweist auf die korrespondierende Literatur

Schlüsselwörter: Lungenfunktion, volumetrische Kapnographie, Lungenfunktionstest, Pulmologie

Recurrent airway obstruction (RAO), also known as heaves, is a form of the syndrome known as equine chronic obstructive pulmonary disease (COPD) and is a hypersensitivity to the dust, molds, mites and spores in the environment of a susceptible horse (Marti et al. 1991; Halliwell et al. 1993). It is now clear that equine 'heaves' is characterized by reversible airway constriction that is due to bronchospasm apart from mucous swelling and secretion. In this regard, it more closely resembles human asthma than human COPD, which is a progressive disease with little reversibility that is usually related to smoking.

Recurrent airway obstruction plays a crucial role in equine medicine. In a study of Swiss and German horses, in which the diagnosis was based on abnormal lung sounds, and the presence of airway secretions containing neutrophils, the incidence of lower airway disease was $54 \%$, respectively $52 \%$ (Bracher et al. 1991, Herholz 1993).

The main lesion of RAO in horses is bronchiolitis characterized by diffuse epithelial hyperplasia, mucus plugging of airways and neutrophilic, lymphocytic and plasmacytic infiltrates and hypertrophy of bronchiolar musculature (Thurlbeck and Lowell 1964; Gerber 1973, Robinson et al. 1996). In many instances the onset of disease is insidious and the owner is unaware of exactly when clinical signs started (Herholz 1993).
Clinical signs range from intolerance to exercise in the performance horse to expiratory dyspnoea, chronic purulent nasal discharge, cough and weight loss in the chronic respiratory patient.

From a functional point of view, respiratory diseases exert their main deleterious effect through factors that alter ventilation to perfusion $(V A / Q)$ ratios throughout the lung. The $V A / Q$ matching of the lung is known to be vital to ensure efficient gas exchange and oxygenation of all body systems. A widening of the range of $V A / Q$ ratios is associated with an increase in the number of alveoli which are either overventilated or underventilated with respect to their perfusion and diffusion capacity. The differences may be evenly distributed throughout the lung or confined to individual lobes and segments. $V A / Q$ disturbances may occur long before clinical manifestations of respiratory disease appear.

Objective quantification of pulmonary function in humans with lower airway disease is currently clinical routine, especially in the early stages of the disease. The most important condition for spirometry in humans are voluntary, sometimes difficult breathing maneuvers, which require patient co-operation. Quantification of pulmonary functional impairment in horses by spirometry is difficult due to the lack of co-operation. In particular difficult to detect and important with regard 
to the prognosis are early and mild stages of pulmonary parenchyma and airway disease.

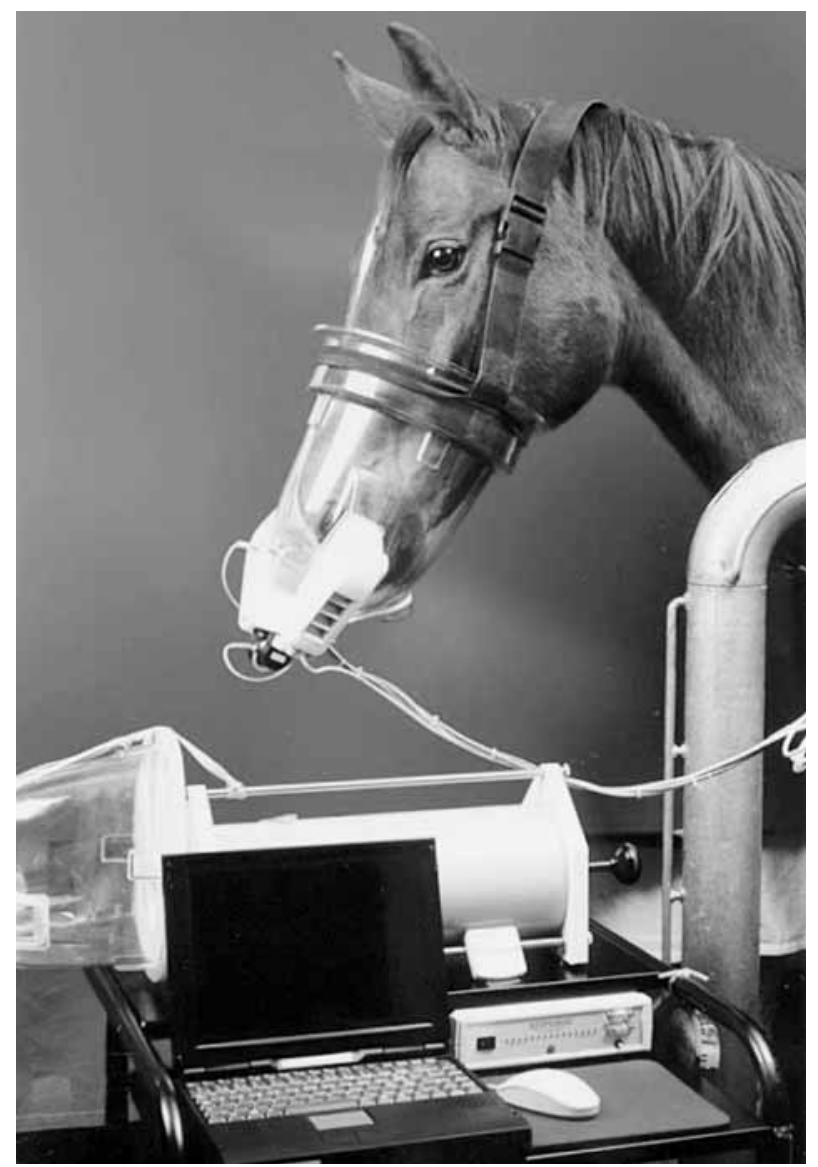

Fig. 1 Ultrasonic spirometry and capnography as a clinically easy applicable tool for generation of volumetric capnograms in the horse

Ultraschallspirometrie und -kapnographie als klinisch einfach anwendbare Methode zur Erstellung volumetrischer Kapnogramme beim Pferd

Pulmonary function tests in horses are dependent on involuntary breathing and meet almost the same requirements as in human neonates and infants. Volumetric capnography is an effort independent method of pulmonary function testing and has not been validated in the awake, spontaneous breathing horse.

\section{A review of literature in equine pulmonary function testing}

Equine pulmonary function testing has traditionally involved horses with clinical signs of lower airway obstruction (Willoughby and McDonell 1979; Robinson et al. 1996, Herholz et al. 2000) and has centered on the evaluation of breathing mechanics via measurements of maximal changes in transpulmonary or pleural pressure, dynamic lung compliance (Cdyn) and pulmonary resistance (RL) using the pneumotachograph-esophageal balloon method (Derksen et al. 1982; Deegen and Stadler 1986). Earlier investigators (Spörri and Leemann 1964; Sasse 1971; Muylle and Oayert 1973) performed transpulmonary pressure measurements directly by placing a catheter within the intrapleural space. Respiratory mechanics have also been measured by forced oscillation techniques (Young et al. 1997). The correlation between the results of forced oscillation technique and the pneumotachograph-esophageal balloon method was good (Young and Tesarowski 1994; Mazan et al. 1999). Tidal breathing flowvolume loops (TBFVL) have been measured by integrated pneumotachography (flowtransducer combined with a pneumotachograph for simultaneous measurements of air flow rate and inspiratory and expiratory volumes). In non-cooperative patients, including human infants (Banovcin et al. 1995; Lodrup Carlsen et al. 1997; Paetow et al. 1999), dogs (Amis and Kurpershoek 1986; Amis et al. 1986), cats (McKierman et al. 1993) and horses (Schatzmann et al. 1974; Connally and Derksen 1994; Petsche et al. 1994; Guthrie et al. 1995) TBFVL have been used to detect airway obstruction. It has been suggested that peak in- and expiratory flows rather represent the elastic than resistive properties of the lungs and are increased in horses with lower airway obstruction (Gillespie et al., 1966, Petsche et al., 1994).

Gas dilution methods (Denc-Sikiric, 1976; Willoughby and McDonell 1979) as well as pletysmography (Leith and Gillespie 1971;Reinhard et al. 1972; Attenburrow 1990 provide measurements of end-expiratory lung volumes (functional residual capacity, FRC). In horses with obstructive pulmonary disease increased FRC have been reported compared to normal horses (Leith and Gillespie 1971; Denac-Sikiric 1976), most likely as a result of air trapping in the alveoli (Robinson et al. 1996).

Arterial oxygen tension $\left(\mathrm{PaO}_{2}\right)$ and alveolar to arterial oxygen tension gradient $\left(\mathrm{AaPO}_{2}\right)$ have also been widely used to assess pulmonary gas exchange, especially in clinical practice (Meister et al. 1976; Willoughby and McDonell 1979; Klein and Deegen 1986).

The short-comings of these established pulmonary function tests are their invasiveness and lack of sensitivity. These measures only detect airway obstruction once it has become relatively severe and is clinically apparent (Willoughby and McDonell 1979; Bayly 2000; Covetil et al. 2001).

Airway obstruction is clinically apparent at rest in horses with RAO in exacerbation or crisis, typically occurring within 24 hours of exposure to hay (Fairbairn et al. 1993), but not in animals with RAO in remission (Robinson 2001). This clinically asymptomatic form of equine lower airway disease is important, however.

The multiple-breath nitrogen washout test may provide a sensitive method to detect clinically inapparent RAO as it remains abnormal in mildly affected horses (Gallivan et al. 1990).

Forced expiration is one the most useful and commonly used pulmonary function tests for the early detection of lower airway disease in humans (West 1997). Recently, a test for airflow obstruction in horses using forced expiration maneuvers has been established which was able to detect mild peripheral airway obstruction (Covetil et al. 2000). However, these methods require expensive equipment and considerable technical assistance and are limited to the larger referral type veterinary clinics.

Flowmetric comparisons of respiratory inductance plethysmography and pneumotachography has been shown to provide 
a defensible method for quantifying airway obstruction in the horse without the need for invasive instrumentation (Hoffmann et al. 2001). However, this method has only been validated in a small population of horses with severe RAO. Further studies are required to determine the repeatability and sensitivity to identify early stages of lower airway disease, as well as the feasibility of this system for field measurements.

Ultrasonic spirometry in combination with capnography as a tool for measurements of volumetric capnograms opened up a method for simple, reliable, economical and rapid pulmonary function testing in equine clinical practice (Buess et al. 1993, Herholz et al. 1997, 2001a). Pulmonary function testing in horses with ultrasonic spirometry can be performed by the investigator and one person for technical assistance. Ultrasonic spirometry is based on the measurement of 2 absolute transit times of sound waves across a tubular sensor from which the flow velocity and volume of breathing can be determined (Figure 2). The inherent advantages of this

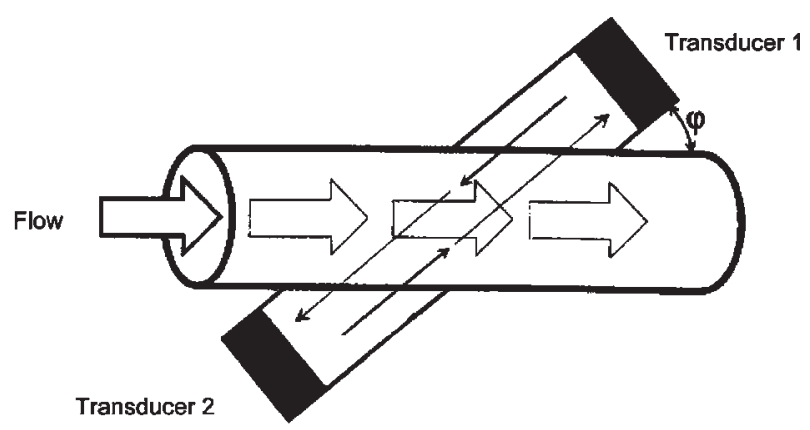

Fig. 2 Measurement of ultrasonic transit times Messung der Ulztaschall-Transitzeiten

method compared to conventional spirometry (integrated pneumotachography) are its linearity and speed, its independence of gas composition, temperature and pressure (Buess et al. 1995).

The effect of the face mask on respiration has been investigated by Holcome et al. (1996). A face mask was designed and fitted to the ultrasonic flow sensor (Buess et al. 1993, Herholz et al. 1997, 2001a), which does not affect respiration and meets the criteria of the American Thoracic Society (ATS; the dead space of the face mask was less than $10 \%$ of the tidal volume, the flow resistance not measurable during tidal breathing at rest and 6 mbar at a flow rate of $100 \mathrm{~L} / \mathrm{s}$ ).

To provide an overview, different pulmonary function tests in the horse, the measurement techniques, advantages and disadvantages of the respective tests are listed in Table 1.

The plot of expired $\mathrm{CO}_{2}$ concentration versus expired volume is called the volumetric capnogram or single breath diagram for $\mathrm{CO}_{2}\left(\mathrm{SBD}-\mathrm{CO}_{2}\right)$. Fowler (1948) divided the concentration volume curve into three distinct phases, relating each phase to the anatomic compartments of the respiratory system in humans. Phase I is the relatively carbon dioxide free washout of the proximal conducting airways. Phase II is the transitional portion of the curve characterized by a rapid upswing as the alveolar gas surges mouthward and mixes within the conducting airways. Phase III represents the gases from the acini or peripheral alveolated airway and is known as the alveolar plateau.

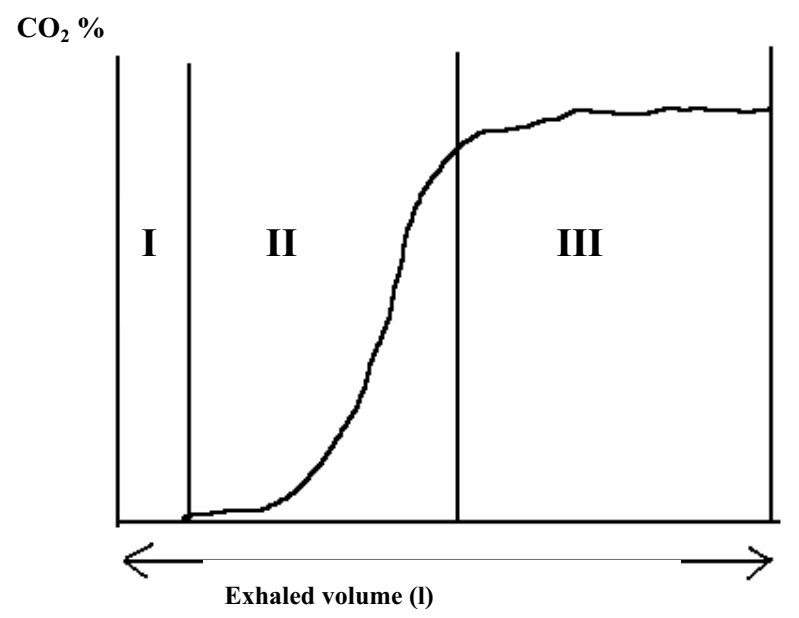

Fig. 3 The three phases of the volumetric capnogram Die drei Phasen des volumetrischen Kapnogramms

There are two different approaches in evaluating volumetric capnograms. The first one is to analyze the shape of the $\mathrm{CO}_{2}$ volume curve in healthy individuals and those with lower pulmonary disease. The second approach is to analyze pulmonary function indices derived from the volumetric capnogram. These are different dead space indices (e.g. dead space fraction according to Bohr's equation,. physiological and alveolar dead space fractions) and indices of efficient $\mathrm{CO}_{2}$ elimination from the lungs.

\section{Challenges in research}

Starting on working with ultrasonic spirometry and capnography pulmonary function testing for the observer the most obvious occurring change was the shape deformity of volumetric capnograms with increasing degree of lower airway obstruction. The aim of the author and co-workers was to investigate, whether the shape analysis of volumetric capnograms is a useful tool to describe pulmonary functional disturbances and to discriminate horses with different degrees of lower airway obstruction. The authors were interested in the variability and reliability of volumetric capnography indices of horses breathing at rest and after application of a centrally acting respiratory stimulant (Lobelin ${ }^{\circledR}$ ). The validity of these indices in diagnosing different degrees of lower airway obstruction were investigated and compared to the clinical examination. Also the precision was investigated with which clinical signs and the ${ }^{99 \mathrm{~m} T c-D T P A}$ clearance from the lung as an index of alveolar integrity can predict pulmonary functional disturbances in horses with different degrees of lower airway obstruction. It was hypothized that age, sex and usage of the horses have significant effects on pulmonary function estimated by volumetric capnography and have to be considered

Table I.(pp 368-369) Equine pulmonary function tests; measuring technique, measured and derived pulmonary function indices, advantages and disadvantages of the different techniques.

Lungenfunktionstests beim Pferd, Messtechniken, Lungenfunktionsindizes, Vor- und Nachteile der unterschiedlichen Verfahren 


\begin{tabular}{|c|c|c|c|c|c|c|c|}
\hline 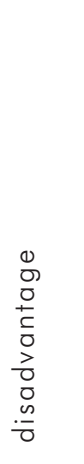 & & 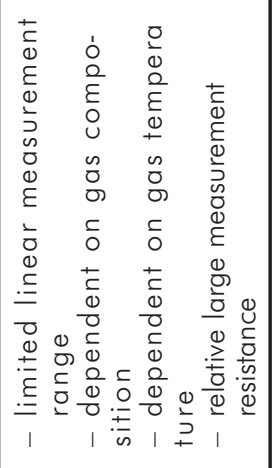 & 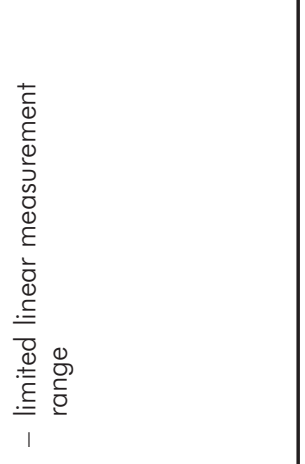 & 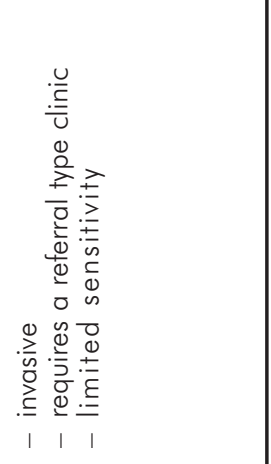 & 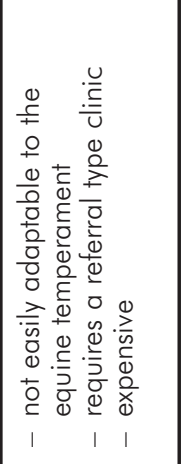 & 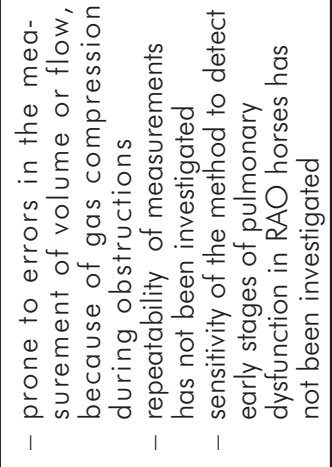 & 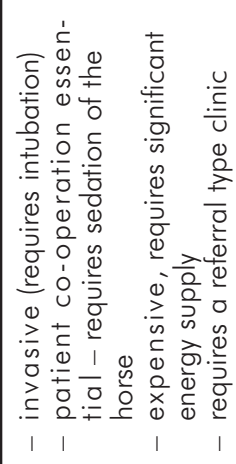 \\
\hline $\begin{array}{l}0 \\
0 \\
0 \\
0 \\
+ \\
0 \\
\frac{0}{0} \\
0\end{array}$ & & 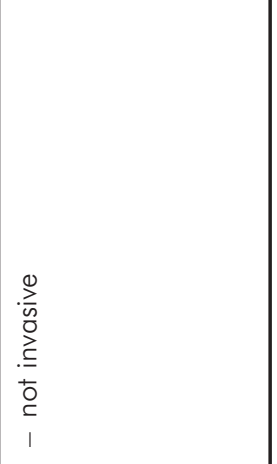 & 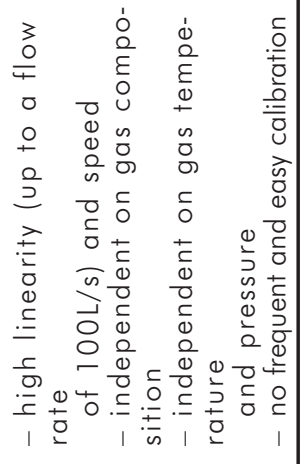 & 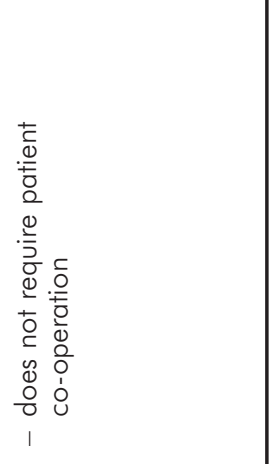 & & 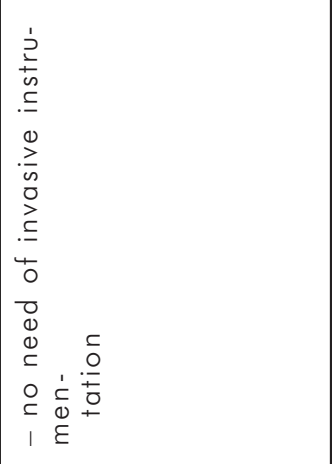 & 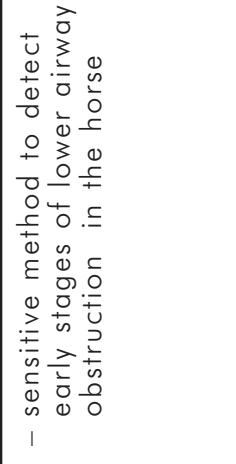 \\
\hline 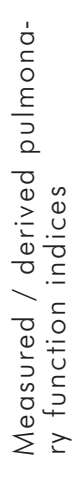 & & 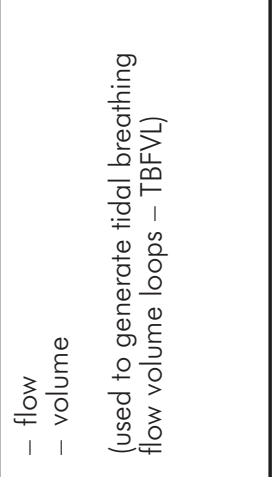 & 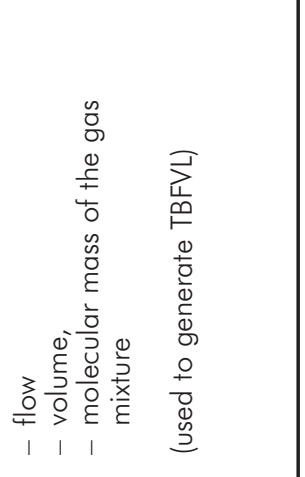 & 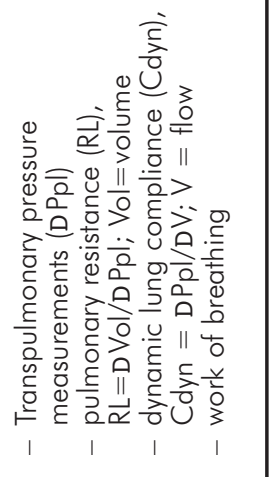 & 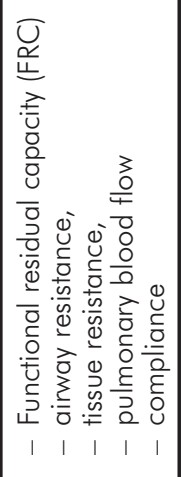 & 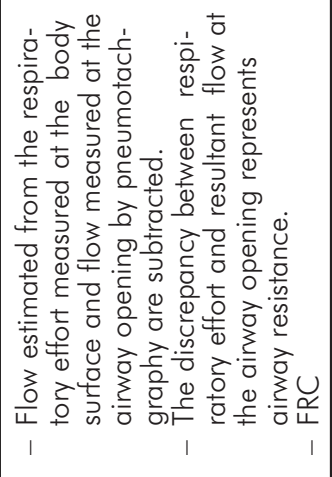 & 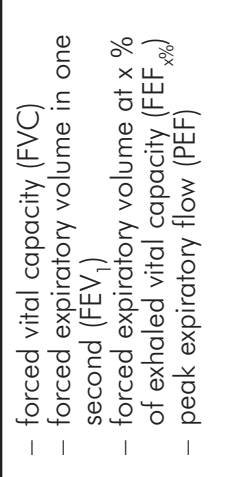 \\
\hline 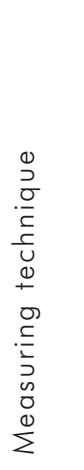 & 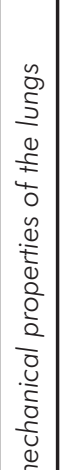 & 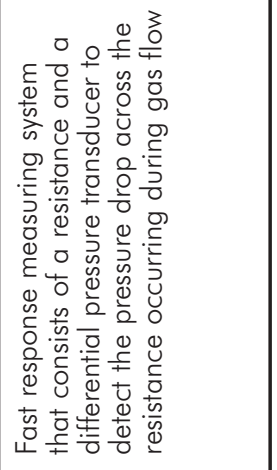 & 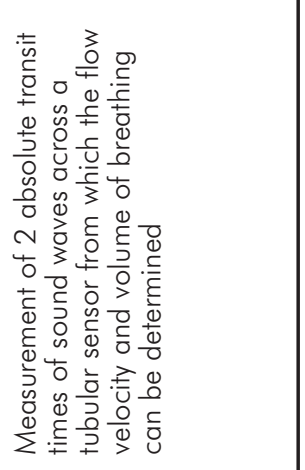 & 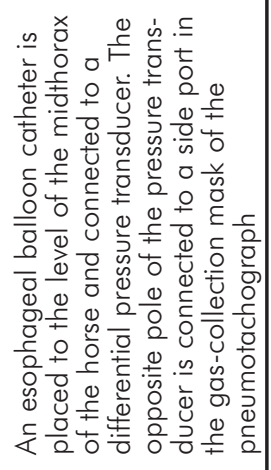 & 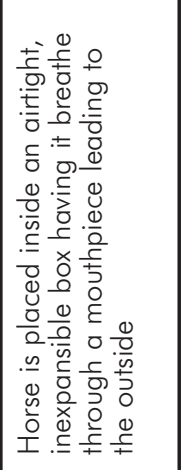 & 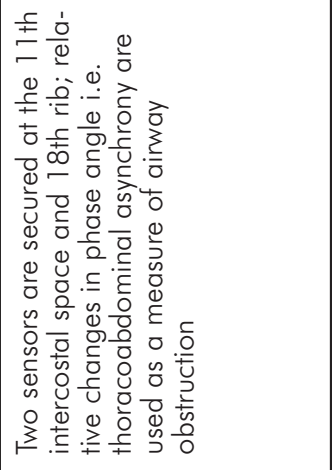 & 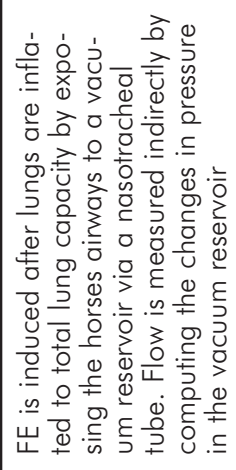 \\
\hline 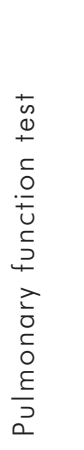 & 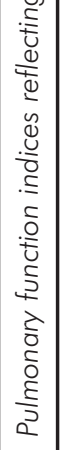 & 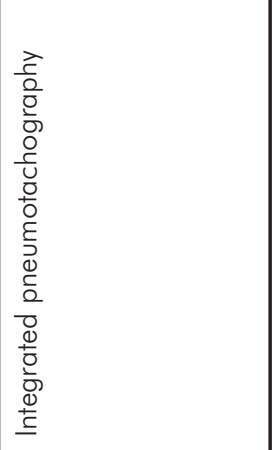 & 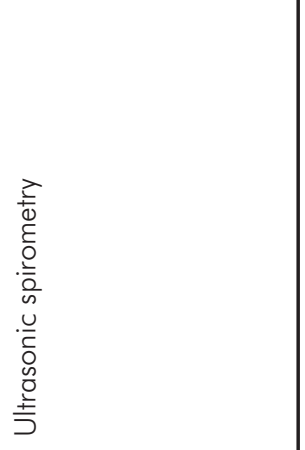 & 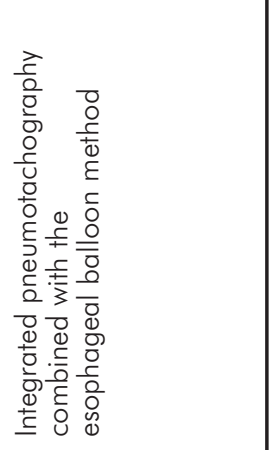 & 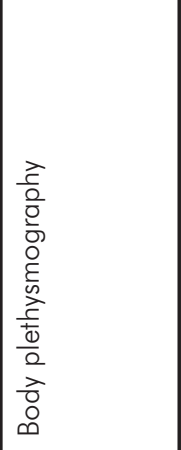 & 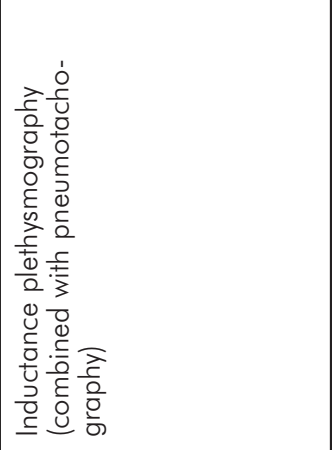 & 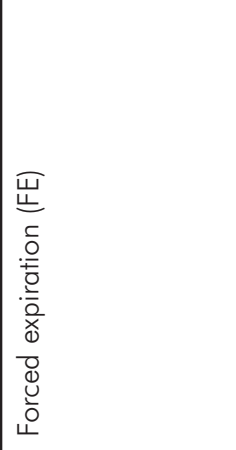 \\
\hline
\end{tabular}




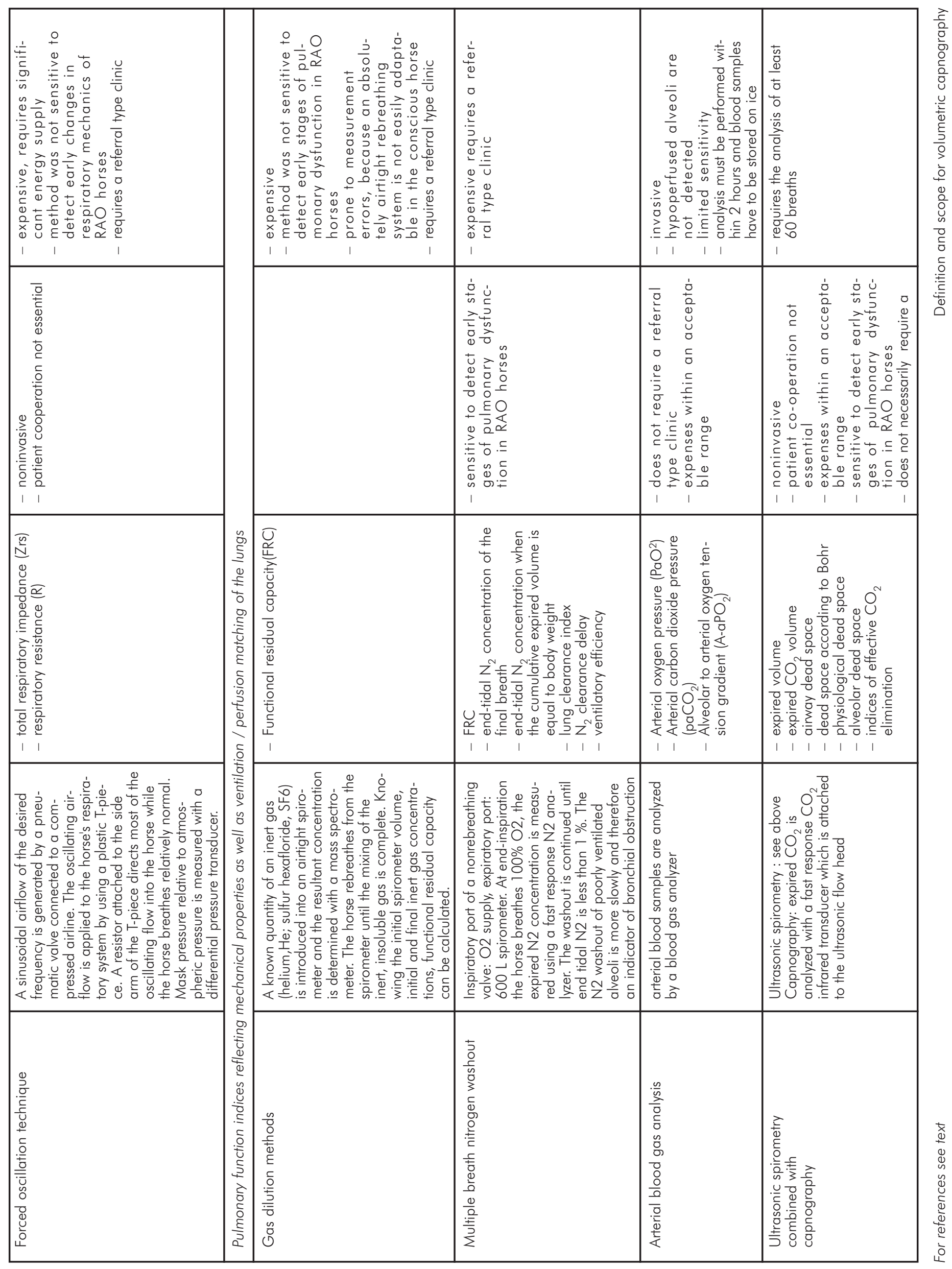


in interpreting pulmonary function testing results. Furthermore, one assumed that by considering the effects of age, sex and usage of the horses on pulmonary function the ability of tidal breathing flow volume loop (TBFVL) indices to detect even minor pulmonary functional changes is increased compared with studies which did not consider these effects.

Finally, the goal was to show that volumetric capnography indices identify pulmonary dysfunction in asymptomatic RAO horses by using the before mentioned interpretative strategies.

\section{The shape analysis of volumetric capnograms}

The shape of the volumetric capnogram is modified by airway obstruction and the evaluation of this deformation could allow an indirect measurement of bronchial patency in horses with RAO.

In healthy humans the volumetric capnogram has a nearly rectangular shape (Ulmer 1970, Fletcher 1980). In human patients with pulmonary disease changes occurring in the shape of the volumetric capnogram are a blurring of the transition between Phase II and III and increased Phase III slopes (Ollson et al. 1980; Fletcher 1986; Schwardt et al.1991, 1994).

Wolff et al. (1989) described the difficulty in interpreting and distinguishing different phases of the volumetric capnogram

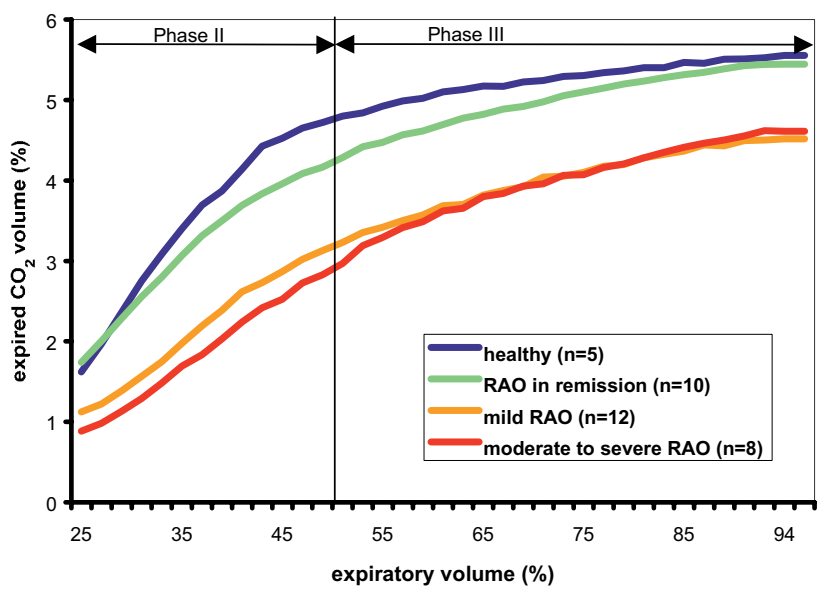

Fig. 4 The shape of volumetric capnograms in horses with different degrees of lower airway obstruction (Herholz et al. $2001 \mathrm{~b})$.

Form des volumetrischen Kapnogramms bei Pferden mit RAO unterschiedlichen Grades (Herholz et al. 2001 b).

of spontaneously breathing humans with most severe lower airway obstruction. The division of the volumetric capnogram into strict definitions of phases I, II, and III is arbitrary to some extent as the expirogram is a continuous curve influenced by both convection and diffusion (Fletcher et al. 1986).

Based on the proposition of the volumetric capnogram in horses with RAO, analysis of different phases was performed as suggested by Worth (1986) in humans. It was shown, that statistical analysis of the volumetric capnogram is a precise method for the description of shape deformities of the $\mathrm{CO}_{2}$ volume curve in horses with different degrees of lower airway obstruction (Herholz et al. 2001 b, Fig. 4).
Aspects of measurements reliability and validity

More than any other respiratory disease, RAO is characterized by functional and clinical variability: symptoms may be absent, mild or severe. Although pulmonary function tests have been used to evaluate horses with clinically normal lungs and those with chronic lung disease, few comprehensive studies of equine respiratory function are available and the range of reported normal values is large (Spörri and Denac 1970; Muylle and Oyaert 1973; Orr et al. 1975; Willoughby and McDonell 1979; Guthrie et al. 1995).

When you measure a variable in a number of individuals, the results will rarely be the same in all subjects and the scatter can be due to the biological variability and experimental errors. It is known that equipment, technique, time of the day, season, medications and the actual state of pulmonary health of the patient each influence the results of pulmonary function tests (Snider et al. 1967; Thiruvengadam et al. 1969; Hruby and Butler 1975; Rozas and Goldman 1982). Therefore, the investigator should attempt to control most of the factors known to affect the variability of pulmonary function tests for results that reflect the true lung function of an individual.

However, the precision of pulmonary function tests in spontaneous breathing horses is limited owing to high breath-tobreath variability in tidal volumes and flow rates (Gallivan et al. 1990; Herholz et al. 1997). Because the tidal breath volume and frequency are closely related to $\mathrm{CO}_{2}$ elimination from the lung, multiple breaths should be considered for precise interpretation of pulmonary function tests.

The selection of five (Ohnesorge et al. 1998) or ten (Covetil et al. 2001) breath cycles can lead to imprecise results and might not reflect the actual state of pulmonary health in a given patient. The averaged measurements over at least 60 breath cycles, have been shown to assure good repeatability (Herholz et al. $2001 \mathrm{a}, \mathrm{c}$ ) of pulmonary function indices derived from volumetric capnography. Assuming a respiratory frequency of $16 / \mathrm{min}$, the corresponding measurement times would be about four minutes; during that time conscious horses tolerate a face mask without problems. On the other hand, up to 974 breaths were required for precise calculation of the slope of phase II and III of the volumetric capnogram. Although the model of the statistical shape analysis is precise in the description of shape deformities, it is not necessarily a useful test to discriminate horses with different degrees of lower airway obstruction (Herholz et al. 2001 a, c).

In order to determine the variability of pulmonary function at levels of ventilation above normal tidal breathing, pulmonary function tests have been performed during exercise (Art and Lekeux 1988; Connally and Derksen 1994). Exercise testing may be contraindicated due to age, lack of fitness, the presence of other pre-existing conditions (e.g. lameness) or temperament.

An alternative approach is the use of respiratory stimulants, e.g. lobeline hydrochloride. In the study of Marlin et al., (2000) the lobeline-induced hyperpnoea was highly reproducible, with no significant effect on breathing mechanics.

In the evaluation of volumetric capnography indices stimulating respiration with lobeline gave no advantage in the repe- 

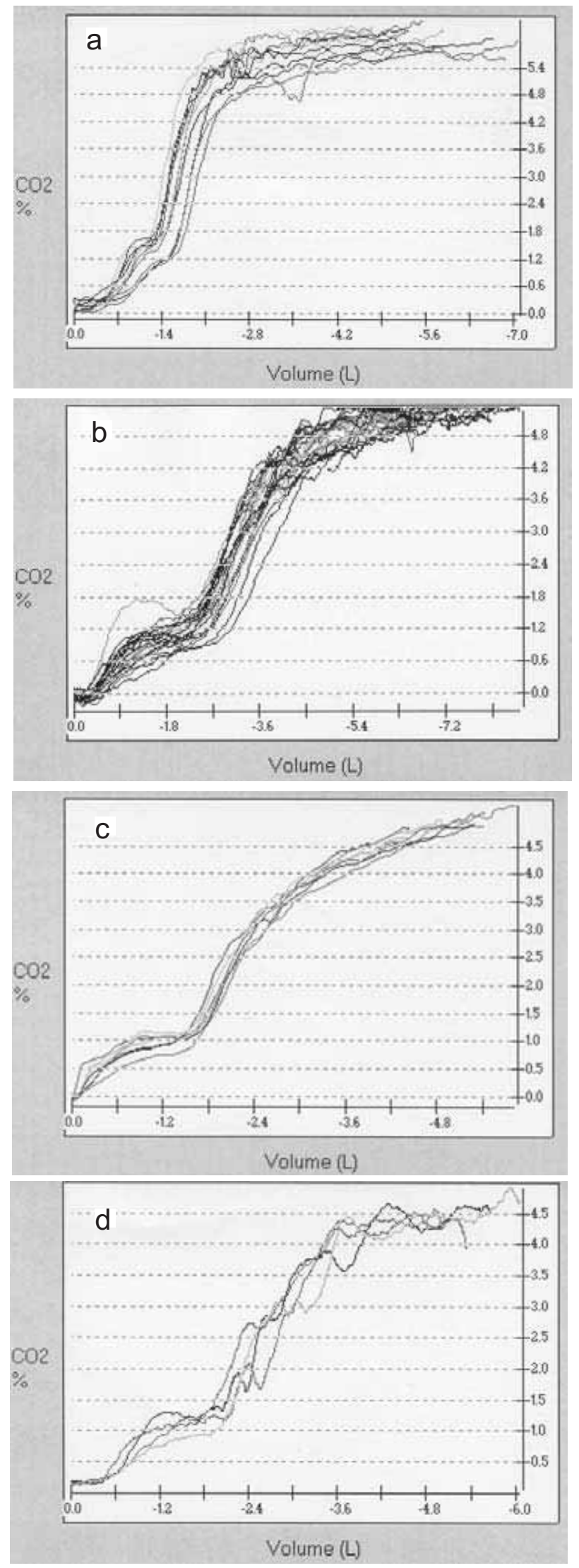

Fig. 5a-d Intra-individual breath-to-breath variability and interindividual variability of volumetric capnograms in horses with different degrees of lower airway obstruction. a: healthy, b: RAO in remission, c: mild RAO, d: RAO in exacerbation.

Intraindivuelle Atemzugsvariabilität und interindividuelle Variabilität des volumetrischen Kapnogramms bei Pferden mit RAO unterschiedlichen Grades atability of these indices or in differentiating between horses with different degrees of RAO (Herholz et al. 2001c). The quality of measuring devices is often described by the reliability or repeatability and the validity of a diagnostic test is described by the terms 'sensitivity' and 'specificity'. Diagnostic tests are not always precise, may give false positive or false negative results and lead to an incorrect classification of an animal as ill or healthy. The degree of misclassification can be quantified by comparing the diagnostic methods available with a 'Gold-standard' or to what is considered to be the best experienced method at hand. Strictly defined the Gold-standard is a diagnostic test with a $100 \%$ accuracy. The sensitivity of a test is the probability that a truly diseased animal will be classified as diseased using the test. The specificity of a test, is the probability that a truly non-diseased animal will be classified as non-diseased with the same test.

To the authors knowledge, there are no studies available describing the sensitivity and specificity of pulmonary function tests. Although far away from a Gold-standard, the clinical examination of the respiratory tract is the best experienced diagnostic method at hand. The validity of volumetric capnography pulmonary function indices has been established compared to the clinical examination as a reference method (Herholz et al. 2001d).

Further efforts should be done in the validation of diagnostic tests, since a Gold-standard might not be the best suited method in practice, but complex, expensive and time-consuming.

However, the validity of volumetric capnography indices estimated by Herholz et al. (2001d) can be regarded as a trend validation with reasonable results compared to the clinical examination.

\section{Clinical, pathophysiological and functional relationships}

To diagnose airway obstruction and evaluate the response to treatment, the clinician must judge the severity of respiratory distress based on clinical signs. These include contraction of the abdominal muscles at the end exhalation, flaring of the nares, respiratory frequency, the presence of cough and nasal discharge, excess mucoid exudates and neutrophilic inflammation within the airways. Clinical signs are regularly used to differentiate horses with airway obstruction from controls (Bracher et al. 1991, Herholz 1993, Tesarowski et al. 1994) and to determine the response to treatment (Dieckmann 1987; Traub-Dargatz et al. 1992; Herholz 1993, Rush et al. 1998). It is currently impossible for the clinician to draw functional conclusions from the results of the clinical examination of the respiratory tract and it seems inappropriate to rely on the arterial blood gas analysis, only (Spörri and Denac 1970). Excellent studies on the relationship between clinical, structural and functional changes in horses with RAO have been performed (Viel 1983; Nymann et al. 1991; Rodrigues et al. 2000).

The accuracy with which clinical signs predict the degree of airway obstruction has been a challenge for further research and was investigated by Robinson et al. (2000) and Herholz 
et al. (2002b). Although clinical symptoms (nasal flare, abdominal movement) identified the worsening of airway obstruction, changes in pulmonary function estimated by maximal change in pleural pressure during tidal breathing, pulmonary resistance and dynamic compliance were considerable before they were first recognized by the clinical evaluator (Robinson et al. 2000). Robinson et al. (2000) concluded, that there can be important pulmonary functional disturbances before the onset of clinical signs, airway disease is probably under-diagnosed and a convenient pulmonary function test would improve the diagnosis and evaluation of the response to therapy.

It was shown by the author, that the subjective, estimated viscosity of tracheobronchial mucus and the percentage of polynuclear neutrophils in the cytology of tracheobronchial secretions was significantly related to pulmonary function indices derived from the volumetric capnogram not only in horses with severe clinical signs of airway obstruction, but also in horses with RAO in remission and in horses with mild symptoms of lower airway obstruction (Herholz et al. 2002b). One approach in assessing the pathophysiology in pulmonary gas exchange is the indirect measurement of alveolar epithelial integrity by the clearance rate of $99 \mathrm{~m}$ technetium-diethylenetriaminepentaacetate $\left({ }^{99 \mathrm{~m} T \mathrm{c}-\mathrm{DTPA})}\right.$ aerosol from the lung (Votion et al. 1999).

The normal alveolar-capillary membrane acts as a semi-permeable membrane and is therefore vital for efficient gas exchange (Jones et al. 1982). The rate of the ${ }^{99 \mathrm{mTC}}$-DTPA clearance was negatively and significantly correlated with pulmonary function indices derived from the volumetric capnogram (Herholz et al. 2001d).

The correlations found by the authors were dependent on the clinical status of pulmonary health which demonstrates the association between the epithelial alveolar integrity estimated

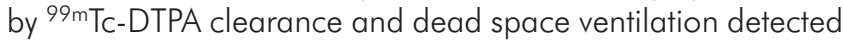
by volumetric capnography.

Aspects of population criteria in diagnosing different degrees of pulmonary disease

Studies of the influence of factors such as age, sex and usage on pulmonary function have not been performed in healthy horses and are required in order to interpret measurements made in those with respiratory disease.

In adults and older children, it is well established that ethnic group is an important determinant of lung function (American Thoracic Society 1991; Stocks et al. 1997) with both lung volumes and forced expiratory flows tending to be lower in black, than white subjects. Several studies have suggested that pulmonary function is diminished, and respiratory illness more common in boys than girls during both infancy and childhood (Tepper et al. 1986). In adults a significant sex times age interaction term showed that healthy elderly men do lose pulmonary function at a faster rate when compared with healthy elderly women (Griffith et al. 2001).

Few studies focussing on the age, sex and usage-specific effects on equine pulmonary function have been published over the last twenty years. One study reported on the effect of age on pulmonary function in a population of five ponies (Derksen et al. 1982). Aguilera-Tejero et al. (1998) investigated the effect of age on arterial blood gases in each sixteen healthy young and aged horses.

It was therefore hypothesized, that age, sex and usage of the horses is a considerable source of variation in the results of pulmonary function indices and that disease related differences in pulmonary functional indices may consequently be obscured by these effects.

The author has done research to investigate the before mentioned effects on volumetric capnography indices (Herholz et al. 2001e, 2002c,d). Furthermore, it has been shown, that the differentiating power of already established TBFVL pulmonary function indices increases by considering these effects (Herholz et al. 2002e).

Accounting for the significant effects of age, sex and use of the horses in inhomogeneous populations optimized the differentiating ability of pulmonary function indices (Herholz et al. 2002c,d,e). By using this interpretative strategy we have shown, that different lung function tests can detect airway obstruction in horses with mild, even clinically inapparent lower airway disease.

\section{Conclusion}

Statistical analysis of the volumetric capnogram is a precise method for the description of shape deformities of the $\mathrm{CO}_{2}$ volume curve in horses with different degrees of lower airway obstruction. To average measurements over at least 60 breath cycles has been shown to assure good reliability of volumetric capnography indices. The sensitivity and specificity of volumetric capnography indices in diagnosing different degrees of lower airway obstruction compared to the clinical examination was reasonable and was highest for the physiological dead space / tidal volume ratio and the index A1/A2 as an index of effective $\mathrm{CO}_{2}$ elimination.

Pulmonary functional indices derived from volumetric capnograms correlate with the severity of clinical signs and the alveolar integrity estimated by the ${ }^{99 \mathrm{mT}} \mathrm{T}$-DTPA clearance in horses with varying degrees of lower airway disease. In a multivariate statistical model the significant effects of age, sex and usage of the horses on pulmonary function were considered, which enabled us to identify pulmonary dysfunction estimated by volumetric capnography in horses with clinically asymptomatic and mild RAO.

Volumetric capnography by the use of ultrasonic spirometry and capnography offers a simple, non-invasive, effort independent, economical and sensitive method for pulmonary function testing in the awake, spontaneous breathing horse. Strategies presented by the author opened up new horizons in the interpretation of pulmonary function testing results in horses with lower airway obstruction.

\section{Outlook}

Future research should involve studies on the pathogenesis and pathophysiology of RAO with the use of volumetric capnography, which proved to detect even minor functional changes of the lungs: One of the major functional abnorma- 
lities in human asthma is the bronchial hyperreactivity and the capacity for acute airway narrowing. The potential severity of acute airway narrowing in the individual patient is likely to be reflected by the maximal response to inhaled bronchoconstrictor challenges. Indeed, it has been demonstrated that the maximal degree of airway narrowing (e.g. response to metacholine) is associated with the severity of asthma symptoms (James et al. 1992). A study in rats (Pétak et al. 1997) demonstrated, that an intravenous Metacholine infusion induced purely airway constriction, whereas aerosolized Metacholine administration gave rise to constriction both in the airways and in the parenchyma. It will be interesting to study respiratory functional responses to intravenous and aerosolized Metacholine using volumetric capnography in horses with $\mathrm{RAO}$ and to correlate the severity of the responses to clinical symptoms.

Volumetric capnography enables to interpret the significance of pathophysiological and functional changes caused by allergens, in particular recombinant mould allergens (Eder et al. 2000), in RAO horses. A previous study suggested that recombinant mould allergens may be involved in the pathogenesis of RAO, as affected horses had significantly higher serum lgE levels against some recombinant mould allergens than healthy animals. Bronchial provocation with these allergens and detection of functional changes with volumetric capnography will determine the role of these recombinant allergens in the pathogenesis of RAO. These investigations may finally lead to set up bronchoprovocation tests with recombinant allergens which allow to predict horses susceptible for RAO.

It is of pathophysiological interest to relate volumetric capnography pulmonary functional indices to objective measurements of the rheological properties of mucus (Gerber et al. 2000) in horses with RAO. Possibly, the observed relationship between volumetric capnography indices and subjective, endoscopically made estimation of mucus viscosity (Herholz et al. 2002 b) can be confirmed by these objective rheological measurements.

Currently, the ${ }^{99 \mathrm{~m} T c-D T P A}$ clearance is the most sensitive indicator of lung damage in the horse (Votion et al. 1999). It will be of major interest to look at the sensitivity and specificity of volumetric capnography indices compared to the $99 \mathrm{~m}$ Tc-DTPA clearance as a Gold-standard in larger populations of horses with different usage.

\section{Abbreviations}

$\mathrm{AaPO}_{2}$ : alveolar to arterial oxygen tension gradient

Cdyn: dynamic lung compliance

COPD: chronic obstructive pulmonary disease

FEV 1: forced expiratory volume in one second

FRC: functional residual capacity

$\mathrm{PaO}_{2}$ : arterial oxygen tension

RAO: recurrent airway obstruction

$\mathrm{RL}$ : pulmonary resistance

$\mathrm{SBD}-\mathrm{CO}_{2}$ : single breath diagram for carbon dioxide

TBFVL: tidal breathing flow volume loops

99mTc-DTPA: ${ }^{99 m}$ technetium-diethylenetriaminepentaacetate

$\mathrm{VA} / \mathrm{Q}$ : ventilation to perfusion ratio

\section{Literature}

Aguilera-Tejero E., Estepa J.C., Lopez I., Mayer-Valor R. and Rodriguez M. (1998): Arterial blood gases and acid-base balance in healthy young and aged horses. Equine Veterinary Journal 30, 352-354

American Thoracic Society (1991): Lung function testing: selection of reference values and interpretative strategies. American Review of Respiratory Disease 144, 1202-1218

Amis T.C. and Kurpershoek C. (1986): Tidal breathing flow-volume loop analysis for clinical assessment of airway obstruction in conscious dogs. American Journal of Veterinary Research 47, 10021006

Art T. and Lekeux P. (1988): A critical assessment of pulmonary function testing in exercising ponies. Veterinary Research communications 12, 25-39

Attenburrow D. P. (1990): Impedance plethysmography. Equine Veterinary Journal 22,114-117

Banovcin P., Seidenberg J. and Von Der Hardt H. (1995): Assessment of tidal breathimg patterns for monitoring of bronchial obstruction in infants. Pediatric Research 38, 218-220

Bayly W. (2001): Lung function: limitations of current methods. Equine Veterinary Journal 33, 7

Bracher V., von Fellenberg R., Winder C. N., Grünig G., Hermann M. and Krähenmann A. (1991): An investigation of the incidence of chronic obstructive pulmonary disease (COPD) in random population of Swiss horses. Equine Veterinary Journal 23, 136-141

Buess C, Guggenbühle W und Harnoncourt K (1995): Technologie der Ultraschall-Spirometrie. Atemwegs-, Lungenkrankheiten 21, 438-442

Buess Ch., Isler R., von Plocki K. A., Auer J. and Guggenbühl W. (1993): Konstruktion eines Messgerätes zur präzisen Analyse der Lungenfunktion beim Pferd in Ruhe und unter Belastung. Pferdeheilkunde, 9, 151-155

Connally B.A. and Derksen F.J. (1994): Tidal breathing flow-volume loop analysis as a test of pulmonary function in exercising horses. American Journal of Veterinary Research 55, 589-594

Couetil L L, Rosenthal FS and Simpson C.M (2000): Forced expiration: a test for airflow obstruction in horses. American Journal of Veterinary Research 88:1870-1879

Couetil L.L, Rosenthal F.S, DeNicola D.B and Chilcoat C.D (2001): Clinical signs, evaluation of bronchoalveolar lavage fluid, and assessment of pulmonary function in horses with inflammatory respiratory disease. American Journal of Veterinary Research 62:538-564

Denac-Sikiric M. (1976): Die funktionelle Residualkapazität und Helium-Einmischzeit gesunder und lungenkranker Pferde. Zentralblatt für Veterinärmedizin Reihe A 23, 193-205

Derksen F.J., Robinson N.E., Slocombe R.F., Riebold T.W. and Brunson D.B. (1982): Pulmonary function tests in standing ponies: Reproducibility and effect of vagal blockade. American Journal of Veterinary Research 43, 598-602

Dieckmann M.P. (1987): Zur Wirksamkeit von Ambroxolhydrochlorid (Mukovent?) bei lungenkranken Pferden - klinische, funktionelle und zytologische Untersuchungen. Dissertation Medicinae Veterinaria; Tierärztliche Hochschule Hannover, Deutschland

Eder., C., Crameri., R., Mayer., C., Eicher., R., Straub. R., Gerber., H., Lazary.S. and Marti E. (2000) Allergen-specific IgE levels against crude mould and storage mite extracts and recombinant mould allergens in sera from horses affected with chronic bronchitis. Veterinary Immunology and Immunopathology 73, 241-253

Fairbairn S.M., Page C.P., Lees P. and Cunningham F.M. (1993): Early neutrophil but not eosinophil or platelet recruitment to the lungs of allergic horses following antigen exposure. Clinical Experimental Allergy 23, $821-828$

Fletcher R, Johnson B, Cumming G and Brew J (1981): The concept of Deadspace with special reference to the single breath test for carbon dioxide. British Journal of Anaesthesia 53:77-86

Fletcher R. (1980): The single breath test for carbon dioxide. PhD Thesis. Berlings, Arlöv, Schweden 
Fletcher R., Niklason L. and Drefeldt B. (1986): Gas exchange during controlled ventilation in children with normal and abnormal circulation: a study using the single breath test for carbon dioxide. Anaesthesia and Analgesia 65, 645-652

Gallivan G.J., Viel. L. and McDonell W.N. (1990): An Evaluation of the Multiple-breath Nitrogen Washout as a Pulmonary Function Test in Horses. Canadian Journal of Veterinary Research 54, 99. 105

Gerber H. (1973): Chronic pulmonary disease in the horse. Equine Veterinary Journal 5, 26-33

Gerber V., King M., Schneider D.A. and Robinson N.E. (2000): Tracheobronchial mucus viscoelasticity during environmental challenge in horses with recurrent airway obstruction. Equine Veterinary Journal 32, 411-417

Gillespie J. R., Tyler W. S. and Eberly V. E. (1966): Pulmonary ventilation and resistance in emphysematous and control horses. Journal of Applied Physiology 21, 416-422

Griffith K. A., Sherill D. L., Siegel E. M., Manolio T. A., Bonekat H. W. and Enright P.L. (2001): American Journal of Respiratory and Critical Care Medicine 163, 61-68

Guthrie A. J., Beadle R. E., Bateman R. D. and White C. E. (1995): Characterisation of normal tidal breathing flow-volume loops for thoroughbred horses. Veterinary Research Communications 19, $331-342$

Halliwell R. E. W., McGorum B. C, Irving P. and Dixon P. M (1993): Local and systemic antibody production in horses affected with chronic obstructive pulmonary disease. Veterinary Immunology and Immunopathology 38, 201-215

Herholz C. (1993): Beeinflussung der Leistung im submaximalen Belastungsbereich durch den Gesundheitszustand der Lunge: eine klinische Studie an 112 Dressur- und Springpferden. Dissertation Medicinae Veterinaria, Universität Bern, Schweiz.

Herholz C., Tschudi P., Gerber H., Moens Y. and Straub R. (1997): Ultrasound spirometry in the horse: a preliminary report on the method and the effects of xylazine and lobeline hydrocloride medication. Schweizer Archiv für Tierheilkunde 139, 558-563

Herholz C., Busato A. und Straub R. (2000): Lungenfunktionsprüfung beim Pferd unter besonderer Berücksichtigung der Ultraschall-Spirometrie / Kapnographie. Schweizer Archiv für Tierheilkunde 142, 299-303

Herholz C., Straub R. and Busato A. (2001a): Ultrasound-Spirometry and Capnography in horses: Analysis of measurements reliability. Veterinary Research Communications 25, 137-147

Herholz C., Straub R., Moens Y. and Busato A. (2001 b): Statistical shape analysis of volumetric capnograms: Evaluation of a new approach for the assessment of pulmonary function in horses with chronic obstructive pulmonary disease (COPD). Journal of Veterinary Medicine A 48, 75-84

Herholz C., Straub R. and Busato A. (2001c): The variability and repeatabilty of indices derived from the single breath diagram for CO2 (SBD- $\left.\mathrm{CO}_{2}\right)$ in horses with COPD and the effect of lobelin hydrochloride on these indices. Veterinary Research communications 25, 401-412

Herholz C., Philipp M, Straub R., Ueltschi G. and Busato A. (2001d): Comparison of lung function indices derived from the single breath diagram for $\mathrm{CO} 2\left(\mathrm{SBD}-\mathrm{CO}_{2}\right)$ and the clearance of 99 mtechnetium-DTPA from the lung in horses with chronic obstructive pulmonary disease (COPD). Journal of Veterinary Medicine line A 48, 553-561

Herholz C., Imhof A., Lüthi S., Straub R. and Busato A. (2001e): Interdisciplinary differences of lung function in elite jumping, eventing and endurance horses assessed by volumetric capnography. Pferdeheilkunde 17, 471-475

Herholz C., Straub R., Lüthi S., MoensY., Imhof A. and Busato A. (2002a): Validity of pulmonary function indices derived from the volumetric capnogram in horses with recurrent airway obstruction (RAO). Research in Veterinary Science 72, 141-146

Herholz C., Straub R., Gerber V., Wampfler B., Lüthi S., Imhof A., Moens Y. and Busato A. (2002b): Relationship between clinical signs and pulmonary function estimated by the single breath diagram for $\mathrm{CO} 2\left(\mathrm{SBD}-\mathrm{CO}_{2}\right)$ in horses with $\mathrm{COPD}$. The Veterinary Journal, in press.
Herholz C., Straub R., Lüthi S., Imhof A. and Busato A. (2002c): Differences of pulmonary function indices derived from the single breath diagram for $\mathrm{CO}_{2}\left(\mathrm{SBD}-\mathrm{CO}_{2}\right)$ in horses related to age, sex and usage. Veterinary Research Communications, in press

Herholz C., Gerber V., Tschudi P., Straub R., Imhof A. and Busato A. (2002d): Volumetric capnography identifies pulmonary dysfunction in horses with clinically apparant and asymptomatic recurrent airway obstruction (RAO). American Journal of Veterinary Research, accepted 2002)

Herholz C., Straub R., Braendlin C., Lüthi S., Imhof A. and Busato A. (2002e): Differences in tidal breathing flow volume loop indices (TBFVL) in horses suffering from recurrent airway obstruction (RAO) considering the utility of the horses. Veterinary Record, accepted, in press

Hoffman A., Kuehn H., Riedelberger K., Kupinskas R. and Miskovic M.B. (2001): Flowmetric comparison of respiratory inductance plethysmography and pneumotachography in horses. Journal of Applied Physiology 91, 2767-2775

Holcombe S.J., Beard W.L. and Hincliffe K.W. (1996): Effect of a mask and pneumotachograph on tracheal and nasopharyngeal pressures, respiratory frequency, and ventilation in horses. American Journal of Veterinary Research 57, 250-253

Hruby J. and Butler J. (1975): Variability of routine pulmonary function tests. Thorax, 30, 548-553

James A., Lougheed D., Pierce-Pino G., Ryan G. and Musk B. (1992): Maximal airway narrowing in a general population. American Review of Respiratory Disease 146, 895-899

Jones J.G., Minty B.D. and Royston D. (1982): The physiology of leaky lungs. British Journal of Anaesthesia 54, 705-721

Klein H.-J. and Deegen E. (1986): Beurteilung von Blutgasparametern des arteriellen Blutes von Pferden unter besonderer Berückksichtigung der alveoloarteriellen Sauerstoffdifferenz. Pferdeheilkunde 2, 331-336

Leith D. E. and Gillespie J. R. (1971): Respiratory mechanics of normal horses and one with chronic obstructive lung disease. Federation Proceedings 30, 556

Lodrup Carlsen K. C., A. Stenzler and K. H.Carlsen (1997): Determinants of tidal flow-volume indices in neonates and children with and without asthma. Pediatric Pulmonology 24, 391-396

Marlin D. J., Roberts C. A., Schroter R. C. and Lekeux P. (2000): Respiratory responses of mature horses in intravenous lobeline bolus. Equine Veterinary Journal 32, 200-207

Marti E., Gerber H., Essich G., Oulehla J. and Lazary S. (1991): The genetic basis of equine allergic diseases. 1. Chronic hypersensitivity bronchitis. Equine Veterinary Journal 23, 457-460

Mazan M. R, Hoffman A. M and Manjerovic N. (1999): Comparison of forced oscillation with the conventional method for histamine bronchoprovocation testing in horses. American Journal of Veterinary Research 60, 174-180

McKiernan B. C., J. A. Dye and E. A. Rozanski (1993): Tidal breathing flow-volume loops in healthy and bronchitis cats. Journal of Veterinary Internal Medicine 7, 388-393

Meister U., Gerber H. and Tschudi P. (1976): Die arterielle Blutgasanalyse in der Diagnostik und Überwachung chronisch lungenkranker Pferde. Schweizer Archiv für Tierheilkunde 1 18, 99-104

Muylle E. and Oyaert W. (1973): Lung Function Tests in Obstructive Pulmonary disease in Horses. Equine Veterinary Journal 5, 37-44.

Nyman G., Lindberg R., Weckner D., Björk M., Kvart C. and Persson S. G. B. (1991): Pulmonary gas exchange correlated to clinical signs and lung pathology in horses with chronic bronchiolitis. Equine Veterinary Journal 23, 253-260

Ohnesorge B., Trötschel C. and Deegen E. (1998): Bestimmung von Totraum und exspiratorischem Mischluftvolumen zur Diagnostik chronischer Lungenerkrankungen beim Pferd. Pferdeheilkunde, 14, 450-455

Ollson S. G., Fletcher R., Jonson B., Nordstrom L. and Prakash O. (1980): Clinical studies of gas exchange during ventilatory support - a method using Siemens-Elma $\mathrm{CO}_{2}$ analyzer. British Journal of Anaesthesia 52, 491 
Orr J. A., Bisgard G. E. and Forster H. V. (1975): Cardiopulmonary measurements in nonanesthetized, resting normal ponies. American Journal of Veterinary Research 36, 1667-1670

Paetow U., D. Windstetter and G. Schmalisch (1999): Variability of tidal breathing flow-volume loops in healthy and sick newborns. American Journal of Perinatology 16, 549-559

Petak F., Hantos Z., Adamicza A., Asztalos T. and Sly P. D. (1997): Metacholine-induced bronchoconstriction in rats: effects of intravenous vs. Aerosol delivery. Journal of Applied Physiology 82, 1479-1487

Petsche M. V., Derksen F. J. and Robinson N. E. (1994): Tidal breathing flow-volume loops in horses with recurrent airway obstruction (heaves). American Journal of Veterinary Research 55, 885891

Reinhardt H. J., Denac M. und Spörri H. (1972): Die Bestimmung des Atemvolumens durch Impedanzmessung beim Pferd. Zentralblatt Veterinärmedizin A 19, 843-850

Robinson, N. E., Derksen, F. J., Olszewski, M. A. and Buechner-Maxwell V. A. (1996): The pathogenesis of chronic obstructive pulmonary disease of horses. British Veterinary Journal 152, 283-306

Robinson N. E., Olszewski M. A., Boehler D., Berney C., Hakala J., Matson C. and Derksen F. J. (2000): Relationship between clinical signs and lung function in horses with recurrent airway obstruction (heaves) during a bronchodilator trial. . Equine Veterinary Journal $32,393-400$

Robinson N. E. (2001): Chairperson's introduction: International Workshop on Equine Chronic Airway Disease, Michigan State University, 16-18 June 2000. Equine Veterinary Journal 33, 5-19

Rodrigues Costa L. R., Seahorn T. L., Moore R. M., Taylor H. W., Gaunt S. D. and Beadle R. E. (2000): Correlation of clinical score, intrapleural pressure, cytologic findings of bronchoalveolar fluid, and histopathologic lesions of pulmonary tissue in horses with summer pasture-associated obstructive pulmonary disease. American Journal of Veterinary Research 61, 167-173

Rozas C. J. and Goldman A. L. (1982): Daily Spirometric Variability. Archive of Internal Medicine 142, 1287-1291

Rush B. R., Raub E. S., Rhoads W. S., Flaminio M. J., Matson C. J., Hakala J. E. and Gillespie J. R. (1998): Pulmonary function in horses with recurrent airway obstruction after aerosol and parenteral administration of beclomethasone diproprionate and dexamethasone. American Journal of Veterinary Research 59, 1039-1043

Sasse H. H. L. (1971): Some Pulmonary Function Tests in Horses: An Aid to Early Diagnosis of Chronic Obstructive Pulmonary Disease ('Heaves') in Horses. PD Thesis, University of Utrecht, The Netherlands

Schatzmann U., Straub R., Gerber H., Lazary S., Meister U. and Spörri H. (1974): Die Elimination von Heu und Stroh als Therapie chronischer Lungenerkrankungen des Pferdes. Tierärztliche Praxis 2, 207-214

Schwardt J. D., Gobran S.R., Neufeld G.R., Aukburg S. J. and Scherer P. W. (1991): Sensitivity of $\mathrm{CO}_{2}$ Washout to changes in Acinar Structure in a Single-Path Model of Lung Airways. Annuals of Biomedical Engineering 19,679-697

Schwardt J. D., Neufeld G. R.., Baumgardner J. E. and Scherer P. W. (1994): NoninvasiveRecovery of Acinar Anatomic Information from CO2 Expirograms. Annuals of Biomedical Engineering 22, 293-306

Snider G. L., Rieger R. A. and Demas T. (1967): Variations in the measurement of spirograms. American Journal of Medical Science 254, 679-684

Spörri H. and Denac M. (1970): Zur Diagnostik intrapulmonaler Ventilationsstörungen. Schweizer Archiv für Tierheilkunde 19, 408417

Spörri H. and Leemann W. (1964): Zur Untersuchung der Lungenmechanik bei Grosstieren. Schweizer Archiv für Tierheilkunde $106,699-713$
Stadler P. and Deegen E. (1986): Diurnal variation of dynamic compliance, resistance and viscous work of breathing in normal horses and horses with lung disorders. Equine Veterinary Journal 18, $171-178$

Stocks J., Henschen M., Hoo A-F., Costeloe K. and Dezateux C. (1997): Influence of ethnicity and gender on airway function in preterm infants. American Journal of Respiratory and Critical Care Medicine 156, 1855-1862

Tepper R. S., Morgan W. J., Cota K., Wright A., Taussing L. M. and The Group Health Medical Associates Pediatricians (1986): Physiologic growth and development of the lung during the first year of life. American Review of Respiratory Disease 134, 513519

Tesarowski D. B., Viel L., McDonell W. N. and Newhouse M. T. (1994): The rapid and effective administration of a beta 2-agonist to horses with heaves using a compact inhalation device and metered-dose inhalers. Canadian Veterinary Journal 35, 170-173

Thiruvengadam K. V., Kamat S. R. and Arunachalam K. (1969): Diurnal and day to day variation in ventilatory capacity and vital capacity in healthy adults. Indian Journal of Chest Disease Allied Science 11, 19-25

Thurlbeck W. M. and Lowell F. C. (1964): Heaves in horses. American Review of Respiratory Disease 89, 82-88

Traub-Dargatz J. L., McKinnon A. O., Thrall M. A., Jones R. L., Bruynincks W., Blancquaert A. M. B. and Dargatz D. A. (1992): Evaluation of clinical signs of disease, bronchoalveolar and tracheal wash analysis, and arterial blood gas tensions in 13 horses with chronic obstructive pulmonary disease treated with prednisone, methyl-sulfomethane, and clenbuterol hydrochloride. American Journal of Veterinary Research 53, 1908-19016

Ulmer W. T., G. Reichel und D. Nolte (1970): Die Lungenfunktion. Verlag Thieme; Stuttgart

Viel L. (1983): Structural-functional correlations of the lung in horses with small airway disease. PhD Thesis, University of Guelph, Ontario, Canada

Votion D. M., Vandenput S. N., Duvivier D. H., Lambert P., vanErck E., Art T. and Lekeux P. M. (1999): Alveolar Clearance in horses with chronic obstructive pulmonary disease. American Journal of Veterinary Research 60, 495-500

West J. (1997): Ventilation. In: Pulmonary Pathophysiology - The Essentials, edited by Kelly P.. Baltimore, MD:Williams \& Wilkins, 315

Willoughby R. and McDonell, A. (1979): Pulmonary function testing in horses. Veterinary Clinics of North America: Large Animal Practice 1, 171-195

Wolff G., Brunner J. X., Bowes C. L., Muchenberger R. and Bertschmann W. (1989): Anatomical and series dead space volume: concept and measurement in clinical praxis. Applied Cardiopulmonary Pathophysiology 2, 299-307

Worth H. (1986): Expiratory partial pressure curves in the diagnostic of emphysema. Bulletin of European Physiopathology in Respiration 22, 191-199

Young S. S. and Tesarowski D. (1994): Respiratory mechanics of horses measured by conventional and forced oscillation techniques. Journal Applied Physiology 76, 2467-2472

Young S. S., Tesarowski D. and Viel L. (1997): Frequency dependence of forced oscillatory respiratory mechanics in horses with heaves. Journal Applied Physiology 82, 983-987

PD Dr. Conny Herholz FTA, ECEIM

Klinik für Nutztiere und Pferde

Universität Bern

Bremgartenstraße 109

$\mathrm{CH}-3012$ Bern

conny.herholz@knp.unibe.ch 